\section{Decreased apoptosis in fatty livers submitted to subnormothermic machine-perfusion respect to cold storage}

\author{
E. Boncompagni, ${ }^{1}$ E. Gini, ${ }^{1}$ A. Ferrigno, ${ }^{2}$ \\ G. Milanesi, ${ }^{1}$ E. Gringeri, ${ }^{3}$ S. Barni, ${ }^{1}$ \\ U. Cillo, ${ }^{3}$ M. Vairetti, ${ }^{2}$ I. Freitas ${ }^{1}$ \\ 'Department of Animal Biology, \\ Histochemistry and Cytometry, Section \\ IGM-CNR, Pavia; ${ }^{2}$ Department of Internal \\ Medicine and Therapeutics, University of \\ Pavia; ${ }^{3}$ Department of Surgical and \\ Gastroenterological Sciences P.G. Cevese, \\ University of Padua, Italy
}

\section{Abstract}

Machine perfusion at subnormothermic temperature $\left(20^{\circ} \mathrm{C}\right), \mathrm{MP} 20$, was developed by Vairetti et al. and showed to afford a better preservation of fatty livers respect to traditional cold storage (CS) in terms of enzyme release into the perfusate, bile production, glycogen stores, energy charge and oxidative stress. Here we investigated whether it also caused decreased cell death by apoptosis. Fatty and lean Zucker rats were submitted to MP20 or CS for $6 \mathrm{~h}$ and reperfused normothermically for 2 h. Apoptotic cells were revealed by immunohistochemistry of activated caspase- 3 and M30 (new epitope on CK18 degraded by caspase-3) and by the TUNEL assay. Portal pressure was also determined. A statistically significant reduction of hepatocyte apoptosis, but especially of sinusoidal cells was determined for fatty livers submitted to MP20 respect to CS. Portal pressure was significantly lower after MP20 respect to CS. The reduction of sinusoidal cell death by apoptosis without need for anti-apoptotic therapies appears particularly positive since apoptotic sinusoidal cells hinder microcirculation in the sinusoids and are thrombogenic. These results further confirm the potential of MP20 for preserving fatty livers that would be otherwise discarded as grafts, and thus for increasing the donor pool for liver transplantation.

\section{Introduction}

The scarcity of organs for transplantation compels to consider the use of marginal organs, in particular of those containing fat, due to alcohol or obesity. ${ }^{1}$ Fatty grafts are more vulnerable to ischemia-reperfusion (I/R) injury than normal livers, and their use has been associated with an increased prevalence of primary non-function or dysfunction after transplantation..$^{2-4}$ Fatty livers (FL) are more liable to $I / R$ injury than normal ones mainly due to increased lipid peroxidation, ${ }^{5}$ neutrophil infiltration, ${ }^{6}$ and Kupffer cells activation, ${ }^{7,8}$ microcirculatory alterations, ${ }^{9-11}$ mitochondrial dysfunction with a lower adenosine triphosphate (ATP) production, ${ }^{12,13}$ and increased sensitivity to oxidative stress. $^{14,15}$

These data reveal how difficult it is to protect steatotic livers from $\mathrm{I} / \mathrm{R}$ injury. Most strategies for reducing damage during acute stress conditions to FL are still in the experimental stage, and are not clinically applicable. Hypothermic machine perfusion (MP) has shown to improve FL preservation compared with cold storage (CS): bile production, ammonia clearance, urea production, oxygen consumption, and ATP levels were significantly higher after MP, compared with CS. ${ }^{16}$ Our group has developed a machine perfusion system with recirculation of an oxygenated medium at $20^{\circ} \mathrm{C}$ (MP20): ATP levels, energy charge, ATP/ADP ratio and bile production, were higher and nitrate/nitrite (NOx) concentration lower, in FL submitted to MP20, respect to CS. Moreover, oxidative stress, tumour necrosis factor (TNF- $\alpha$ ), caspase-3 activity, and biliary alkaline phosphatase release, were lower in FL preserved by MP20. ${ }^{17,18}$ We have also shown a better preservation of FL by MP20, respect to CS, in terms of morphology, glycogen stores and reactive oxygen species (ROS) production. ${ }^{17}$

A key feature of $\mathrm{I} / \mathrm{R}$ in the liver is apoptosis, but little is known about the mechanisms of cell death in FL after CS, and the few available information is controversial. Some authors observed predominant necrotic forms of hepatocyte death after warm I/R. ${ }^{19-21}$

Baskin-Bey et al. found that hepatocyte apoptosis predominated in steatotic grafts after cold ischemia-warm reperfusion, ${ }^{22}$ whereas Fernandez et al. using a different animal model, did not observe apoptosis in steatotic livers undergoing transplantation, after cold preservation-warm reperfusion. ${ }^{15}$ As cold $\mathrm{I} / \mathrm{R}$ is concerned, disagreeing observations have been made, that might be related to different experimental settings, such as the duration of cold ischemia or the different animal models. ${ }^{15,22,23}$ In particular, cathepsindependent hepatocyte death by apoptosis was determined in cathepsin B knockout mice, fed with a methionine/choline deficient diet, after $24 \mathrm{~h}$ of cold preservation with University of Wisconsin (UW) solution and 1 hour warm reperfusion. ${ }^{22}$ By contrast, no apoptosis was
Correspondence: Dr. Eleonora Boncompagni, Histochemistry and Cytometry, Section IGM-CNR, Palazzo Botta 2, via Ferrata 9, 27100 Pavia, Italy. Tel. +39.0382 .986317 - Fax: +39.0382 .986406 .

E-mail: boncompa@unipv.it

Key words: fatty liver, transplantation, apoptosis, sinusoidal cells, sub-normothermic machine perfusion, cold storage.

Acknowledgments: the authors would thank Mr. Gaetano Viani for his skilful technical assistance.

Funding: this research was funded by MIUR-PRIN (2004 and 2006) and by F.A.R. - University of Pavia, Italy. EB was partially funded by Superpig Program, Fund for promoting institutional agreements, Regione Lombardia, Italy.

Received for publication: 12 July 2011.

Accepted for publication: 19 September 2011.

This work is licensed under a Creative Commons Attribution NonCommercial 3.0 License (CC BYNC 3.0).

(C) Copyright E. Boncompagni et al., 2011

Licensee PAGEPress, Italy

European Journal of Histochemistry 2011; 55:e40 doi:10.4081/ejh.2011.e40

identified in Zucker rat liver preserved with UW solution for $6 \mathrm{~h}$ and reperfused for $4 \mathrm{~h},{ }^{15}$ whereas both apoptotic and necrotic cell death was identified in experiments where fatty Zucker rat livers preserved for $6 \mathrm{~h}$ with UW solution were transplanted in lean animals. ${ }^{23}$

We investigated the response of FL to MP20, respect to CS, in terms of cell death by apoptosis. We used the terminal deoxynucleotidyl transferase-mediated deoxyuridine triphosphate nick-end labeling (TUNEL) assay, which identifies apoptosis in all kinds of cell type, by detecting the late events when major DNA fragmentation occurs. ${ }^{24}$ However, DNA fragmentation does not appear in all apoptotic cells ${ }^{25}$ and the extent of apoptosis may be overestimated using TUNEL method, since DNA degradation also occurs during necrosis because of the release of nucleases from infiltrating inflammatory cells. ${ }^{26-27}$ Therefore, we also investigated the expression of activated caspase 3 and of the neo-epitope M30, specific to the Asp396 caspase cleavage site of cytokeratin 18 (CK18) not expressed by viable or necrotic cells. ${ }^{28-29}$ Proteolytic cleavage of cytokeratin 18 during apoptosis takes place before the disruption of cell membrane asymmetry, and before the occurrence of DNA strand-breaks. CK18 is expressed by hepatocytes and bile duct cells, ${ }^{30-31}$ but not by sinusoidal lining cells (SLC). 


\section{Materials and Methods}

\section{Chemicals}

Unless otherwise mentioned, all chemicals were of the highest purity available and were purchased from Sigma (Milano, Italy).

\section{Animals}

Homozygous (fa/fa) obese male Zucker rats (11-12 week old, $375 \pm 15$ g; Charles River, Italy) were used as models of FL32 and heterozygous (fa/-), lean animals $(300 \pm 10 \mathrm{~g})$ were used liver donors. The animals had free access to water and food. The use and care of animals in this study were approved by the Italian Ministry of Health and by the University Commission for Animal Care. Rats were anesthetized with sodium pentobarbital $(40 \mathrm{mg} / \mathrm{kg}$ i.p.) and received 250 units of heparin via the inferior vena cava. The bile duct was cannulated (PE-50), an intravenous catheter (16gauge) was inserted into the portal vein. The liver was washed out with an oxygenated Krebs-Henseleit (KH) medium containing in $\mathrm{mmol} / \mathrm{L}: 118 \mathrm{NaCl}, 4.7 \mathrm{KCl}, 1.2 \mathrm{MgSO}_{4}, 1.2$ KH2PO4, $1.25 \mathrm{CaCl}_{2}, 25 \mathrm{NaHCO}, 20$ HEPES (pH 7.4), 5 glucose and $5 \mathrm{~N}$-acetyl-cysteine (NAC) $\mathrm{pH} 7.4(4 \mathrm{~mL} / \mathrm{min} / \mathrm{g}$ of liver) and removed. ${ }^{32}$ Samples of control livers were obtained from lean and obese rats immediately after washout.

\section{Machine perfusion}

The liver was placed in an organ chamber, and was connected to re-circulating standard perfusion equipment containing $200 \mathrm{~mL} \mathrm{KH}$ medium for $6 \mathrm{~h}$. The $\mathrm{KH}$ solution was recirculated by a roller pump (Gilson Minipuls-3), oxygenated and maintained at $20^{\circ} \mathrm{C}$ by a heat exchanger (Julabo-F12). The perfusion solution was oxygenated by a glass oxigenator, resulting in a pre-hepatic oxygen concentration of 500 to $600 \mathrm{mmHg}$, and in post-hepatic concentration of about $120 \mathrm{mmHg}$ at $37^{\circ} \mathrm{C}$. During MP at $20^{\circ} \mathrm{C}$ the pre-hepatic oxygen concentration was 550 to $650 \mathrm{mmHg}$, and the post-hepatic concentration about $450 \mathrm{~mm} \mathrm{Hg}$ at $37^{\circ} \mathrm{C}$. The perfusate ran freely via the suprahepatic caval vein into the organ chamber, and was immediately re-circulated by the roller pump into the reservoir. Air emboli were removed from the system by a bubble trap. The portal venous pressure was continuously measured throughout the perfusion by means of a water column connected to the portal vein inflow catheter. Pre-calibration was performed each time just before connecting the liver to the circuit. At the end of MP preservation we started normothermic reperfusion by switching to a reservoir containing fresh solution at $37^{\circ} \mathrm{C}$.

\section{Cold storage}

After washout with $\mathrm{KH}$, the livers were flushed in situ with UW for 2 min and maintained at $4^{\circ} \mathrm{C}$ in this solution for $6 \mathrm{~h}$. After CS, livers were washed out of the storage solution by discarding the initial effluent in a non-circulating system with $20 \mathrm{~mL} \mathrm{KH}$ at $37^{\circ} \mathrm{C}$ then subjected to recirculating reperfusion with $\mathrm{KH}$.

\section{Normothermic reperfusion}

Reperfusion with $\mathrm{KH}\left(2 \mathrm{~h}\right.$ at $\left.37^{\circ} \mathrm{C}\right)$ was performed in the same set up as MP, both in MP and CS preserved livers. The portal venous pressure (in $\mathrm{mmHg}$ ) was monitored by a water column connected to the portal vein inflow catheter. Precalibration was performed each time just before connecting the liver to the circuit.

\section{Morphology and immunohisto- chemistry}

Liver pieces were rapidly removed after normothermic reperfusion, fixed in $2 \% \mathrm{p}$ formaldehyde in $0.1 \mathrm{M}$ phosphate buffer at $\mathrm{pH}$ 7.4 for $24 \mathrm{~h}$ and processed routinely until they were embedded in Paraplast wax.

Sections were cut at $5 \mu \mathrm{m}$ and stained with Hematoxylin and Eosin (H\&E) for histological examination.

\section{Electron microscopy}

Samples of the liver were quickly removed, and small fragments were fixed by immersion in $2.5 \%$ glutaraldehyde in $0.13 \mathrm{M}$ Millonig buffer (pH 7.2-7.4) at $4^{\circ} \mathrm{C}$ for $4 \mathrm{~h}$, rinsed, postfixed with $1 \%$ osmium tetroxide at $4^{\circ} \mathrm{C}$ for $2 \mathrm{~h}$, washed, dehydrated through graded concentrations of alcohol, and embedded in Epon. Ultrathin sections were stained with uranyl acetate for $7 \mathrm{~min}$ and lead citrate for $2 \mathrm{~min}$, coated with carbon, and observed with a Zeiss EM 900 electron microscope operating at $80 \mathrm{kV}$.

\section{Activated Caspase-3}

Paraffin sections of $6 \mu \mathrm{m}$ thick were cut and deparaffinized in xylene and rehydrated with graded ethanol and water. Antigen retrieval was performed bringing slides to a boil temperature by microwave in $10 \mathrm{mM}$ citric acid buffer $(\mathrm{pH}$ 6), then maintained at a sub-boiling temperature $(100 \mathrm{~W})$ for $10 \mathrm{~min}$. After cooling, aspecific antibody binding was blocked for $1 \mathrm{~h}$ in PBS with $10 \%$ normal goat serum, $3 \%$ bovine serum albumin, and $1.5 \% \mathrm{NaCl}$. To avoid aspecific background a further block was performed in PBS with 5\% powder milk and $1.5 \% \mathrm{NaCl}$ for 30 min. Primary anti cleaved caspase-3 antibody (Cell Signalling Technology, Beverly, MA, USA) was applied at a dilution of 1:100 in the blocking solution and incubated overnight at $4^{\circ} \mathrm{C}$ in a moist chamber. After rinsing with PBS, a peroxidase-conjugated secondary anti-rabbit antibody (Dual link EnVision System, Dako,
Glostrup, Denmark) was applied to the sections for $30 \mathrm{~min}$ at room temperature. After rinsing with PBS, the liquid 3,3-diaminobenzidine chromogen system (DAB; Dako) was used to visualize the secondary antibody for $5 \mathrm{~min}$. The slides were counterstained with Mayer's Hematoxylin.

\section{M30}

Paraffin sections of $6 u$ m thick were cut and deparaffinized in xylene and rehydrated with graded ethanol and water. Antigen retrieval was performed by microwave treatment with a pre-heated $10 \mathrm{mM}$ citric acid buffer $(\mathrm{pH} 6)$ by incubation in a microwave oven at $100 \mathrm{~W}$ for 20 min, according to the manufacturer's instructions. After cooling, aspecific antibody binding was blocked for $1 \mathrm{~h}$ in PBS with $10 \%$ normal goat serum, 3\% bovine serum albumin, and $1.5 \% \mathrm{NaCl}$. Primary M30 CytoDeath antibody (Peviva, Gromma, Sweden) was applied at a dilution of 1:100 in the blocking solution and incubated overnight at $4^{\circ} \mathrm{C}$ in a moist chamber. After rinsing with PBS, a peroxidase-conjugated secondary anti-rabbit antibody (Dual link EnVision System; Dako) was applied to the sections for $30 \mathrm{~min}$ at room temperature. After rinsing with PBS, the liquid 3,3diaminobenzidine chromogen system (DAB; Dako) was used to visualize the secondary antibody for $5 \mathrm{~min}$. The slides were counterstained with Mayer's Hematoxylin.

Terminal deoxynucleotidyl transferasemediated dUTP nick end-labelling method (TUNEL)

Paraffin sections 6 - $\mu$ m-thick were collected on poly-L-lysine-coated glass slides, and the nuclear DNA fragmentation of apoptotic cells was labeled in situ with the ApopTag Peroxidase in situ Apoptosis Detection Kit (Intergen Co. Purchase, NY, USA). Briefly, the sections were deparaffinized and treated with $20 \mathrm{mg} / \mathrm{mL}$ proteinase $\mathrm{K}$ (Boehringer, Mannheim, Germany) for 15 min. After rinsing with distilled water, the sections were treated with $3 \%$ hydrogen peroxide in $10 \%$ methanol for $15 \mathrm{~min}$. The sections then were washed with distilled water and incubated in the provided equilibration buffer for $10 \mathrm{~min}$. The sections were incubated with terminal deoxynucleotide transferase (TdT) in the provided reaction buffer with digoxigenin-dUTP, in a humidifier chamber at $37^{\circ} \mathrm{C}$ for $1 \mathrm{~h}$. The incorporated digoxigenin-dUTP was detected by peroxidase-conjugated antidigoxigenin antibody and the signal developed by incubation with 3,3-diamino-benzidine (DAB) in the presence of $\mathrm{H}_{2} \mathrm{O}_{2}$. The slides were counterstained with Hematoxylin.

\section{Apoptosis quantification and sta- tistical analysis}

Immunohistochemical sections were exam- 
ined by light microscopy (Zeiss Axioskop 2 Plus light microscope (Carl Zeiss Microimaging, Jena, Germany) and apoptotic cells counted. Ten high-power fields (x 400) for each animal were selected on the basis of the best preserved tissue areas $(n=5$ each treatment). Peripheral areas of tissue sections were not considered. Immunoreactivity was expressed as percentage of stained cells, calculated by dividing the number of stained nuclei by the total number of hepatocytes in any given zone. Statistical analysis was performed using SPSS 13.0 statistical software. General Linear Model, univariate, was used to compare sets of data, with significant differences at $\mathrm{P}<0.05$.

\section{Results}

\section{Morphology - light and electron microscopy}

Morphological observation of control Zucker lean rat liver showed no evidence of steatosis. There were no substantial differences in morphology after CS compared with MP20, and the parenchyma was well-preserved after both treatments (not shown).

Control obese animals showed severe micro- and macrovescicular fatty infiltration in hepatocytes, mainly in the midzone (MZ) (not shown $\left.;^{18}\right)$. In FL submitted to CS, the parenchyma was highly damaged, especially in the MZ and centrolobular region (CL) where sinusoids appeared markedly dilated and hepatocyte ballooning and necrosis were frequent (not shown). By contrast, when FL were submitted to MP20, the parenchyma was much better preserved, the sinusoidal structure was normal, macrosteatosis and vacuolar degeneration of hepatocytes much less abundant, and necrosis was never observed. The analysis of liver ultrastructure further supported the observations. In particular, for FL submitted to MP20, most endothelial cells appeared normal with welldeveloped cytoplasmic processes lining the sinusoid, and without any morphologic evidence of apoptosis. Apoptotic cell morphology was rare in control lean and fatty livers.

On the contrary, CS-preserved FL liver showed frequent SLC apoptosis, in particular of cells with the typical morphology of endothelial, stellate and Kupffer cells (Figure 1). Hypothermic injury to sinusoidal endothelial cells, detachment from the basal lamina, rounding and loss of cytoplasmic processes, were observed. Kupffer cells phagocyting apoptotic bodies were recorded. By contrast, when FL was preserved by MP20, the hepatocytes ultrastructure was less damaged and fewer apoptotic cells were observed.
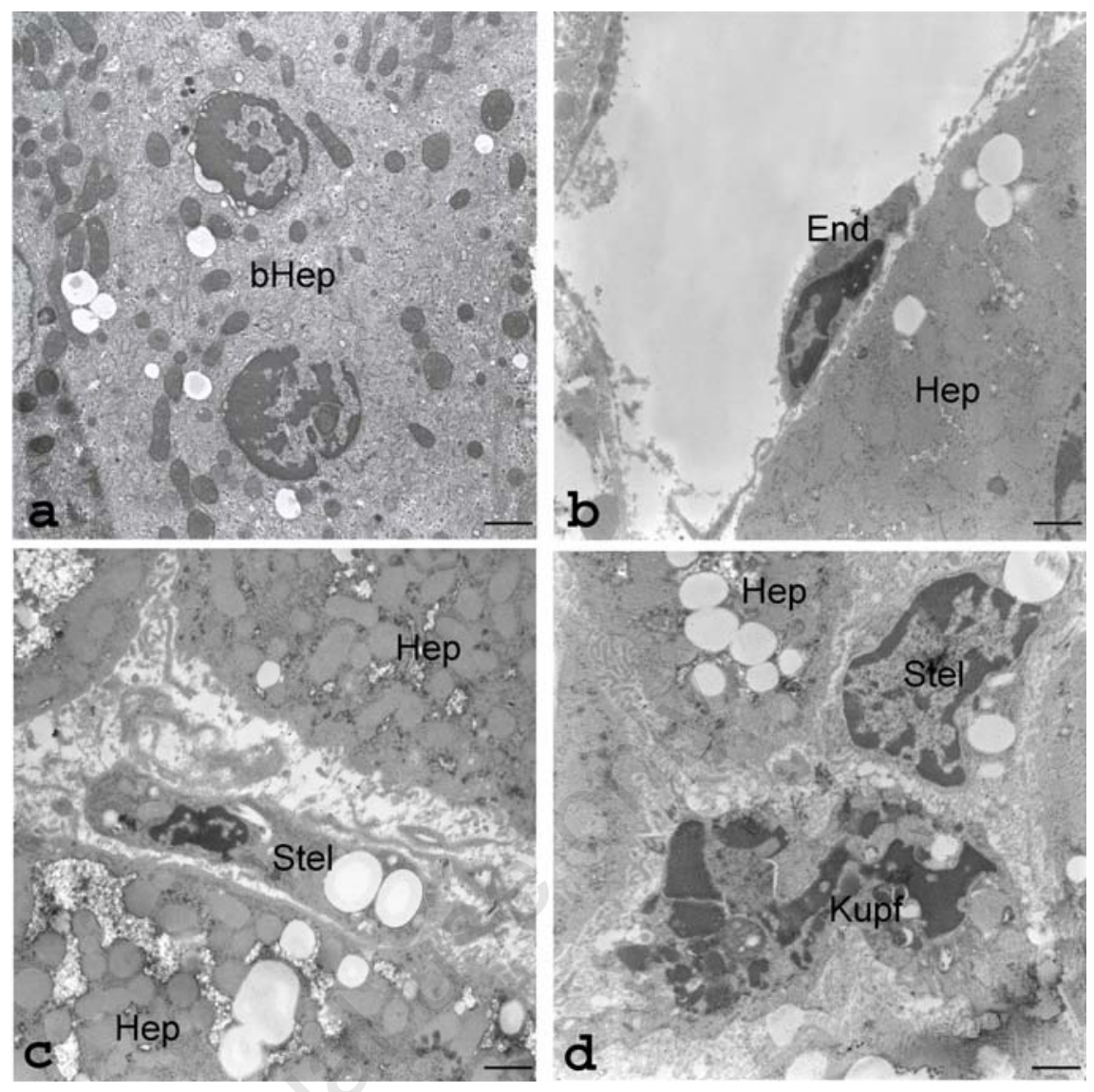

Figure 1. Representative transmission electron micrographs of apoptotic parenchymal and sinusoidal cells in the liver of obese Zucker rats submitted to conventional cold storage (CS) or to Machine Perfusion at $20^{\circ} \mathrm{C}$ (MP20). a), MP20: ultrastructure of an apoptotic binucleated hepatocyte (bHep) with condensed chromatin margination surrounded by dilated nuclear envelope in both nuclei; well-preserved mitochondria, endoplasmic reticulum and storage material (glycogen rosettes and lipid droplets); scale bar: $1.1 \mu \mathrm{m}$. b), CS: ultrastructure of an early apoptotic cell with typical sinusoidal endothelial cell morphology (End). In sharp contrast with MP20 preservation (a), the nearby hepatocyte (Hep) contains swollen, poorly-contrasted mitochondria; scale bar: $1.7 \mu \mathrm{m}$. c), CS: ultrastructure of an apoptotic sinusoidal cell containing lipid droplets and thus presumed to be a stellate cell (Stel). As in b) the neighboring hepatocytes (Hep) contain packed and swollen mitochondria, lipid droplets and intracytoplasmic edema; scale bar: $1.7 \mu \mathrm{m}$. d), CS: ultrastructure of an advanced-stage (karyorrhexis) apoptotic Kupffer cell (Kupf); a nearby sinusoidal cell with abundant rough endoplasmic reticulum and lipid-rich cytoplasm (Stell) and the cytoplasm of a hepatocyte (Hep) with abundant microvilli in the interhepatocyte recess, can also be recognized; scale bar: $1.7 \mu \mathrm{m}$.

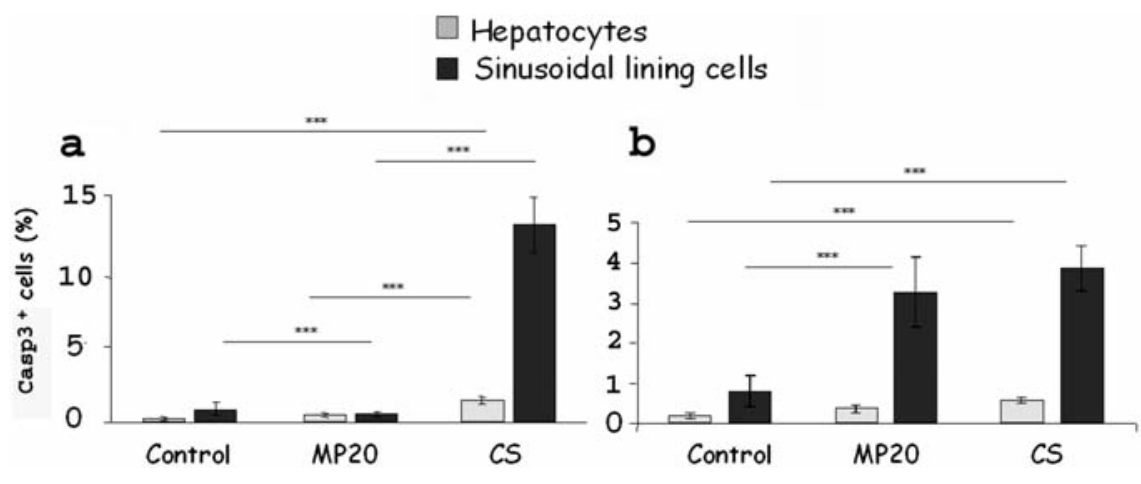

Figure 2. Hepatocytes and SLC death quantified as the percentage of caspase-3 positive cells/ total cells, in 10 random microscopic high-power fields ( 40 objective). Statistically significant decrease of apoptotic hepatocytes and SLC after MP20 respect to CS was observed for obese Zucker rat liver (a), but not for the lean one (b). Values (\%) are reported as mean ( 5 rats each group) \pm standard error; ${ }^{*} \mathbf{P}<0.05$. 


\section{Immunodetection of cleaved caspase-3}

A statistically significant decrease of apoptotic hepatocytes and SLC $(\mathrm{P}<0,05)$ after MP20 respect to CS was observed for obese Zucker rat liver, but not for the lean one (Figure $2 \mathrm{a}, \mathrm{b}$ ). In fatty and lean control livers only few hepatocytes and SLC were positive (Figure 3 a,d) Single positive cells were located mainly in the MZ area both after CS or MP20 (Figure 3 b,c,e,f).

\section{Immunodetection of M30 antigen}

A statistically significant decrease of early apoptotic hepatocytes $(\mathrm{P}<0.05)$ after MP20 respect to $\mathrm{CS}$ was observed, for both lean and obese Zucker rats (Figure 4 a,b). In fatty and lean control livers minimal M30 staining was present (Figure 5 a,d). After both CS and MP20, M30 positive hepatocytes were mainly located in the periportal (PP) and MZ regions. They showed a granular cytoplasmatic staining pattern (Figure 5 b,c,e,f). Most M30-positive cells did not present obvious apoptotic nuclear morphological features, thus supporting the suggestion that immunohistochemical detection of M30 marks an early event in the apoptotic process.

\section{TUNEL reaction}

A statistically significant decrease of apoptotic hepatocytes and SLC $(\mathrm{P}<0,05)$ for obese Zucker rat was observed after MP20 respect to CS (Figure 6a). In lean animals a similar decrease was observed only for SLC (Figure $6 \mathrm{~b})$. Few hepatocytes and SLC were positive to TUNEL staining in control lean and obese livers (Figure 7 a,d). Both after CS or MP20, TUNEL-stained cells were located mainly in PP and MZ area (Figure 7 b,c,e,f).

\section{Portal pressure}

Steatotic livers preserved by CS exhibited a gradual and time-dependent pressure increase (Figure 8a). Conversely, FL preserved by MP at $20^{\circ} \mathrm{C}$ even at the end of reperfusion showed lower pressure values, similar to those observed in livers obtained from lean rats, for which the time-dependent increased pressure was negligible (Figure 8b).

\section{Discussion}

In this study we further strengthen the working hypothesis that MP20 is a better strategy to protect steatotic livers than conventional CS. We have shown in previous reports that not only normal livers ${ }^{17}$ but especially FL, submitted to subnormothermic machine perfusion
(MP20) exhibit a marked damage reduction, evaluated as enzyme and cytokine release, excretory function, energy recovery and oxidative stress. ${ }^{17,18}$ Here we show that MP20 also protects FL from apoptotic cell death. In particular we found a significant reduction of apoptosis of hepatocytes and especially of SLC in FL preserved for $6 \mathrm{~h}$ with MP20 and reperfused respect to livers preserved by $\mathrm{CS}$.

Apoptotic SLC and hepatocytes were more numerous in the PP zone of both CS and MP20 treated livers. The mechanism of the predominance of apoptosis in the PP zone is still unclear. Although PC regions have lower oxygen tensions than PP areas, which may suggest that they would be more susceptible to hypoxic damage, $\mathrm{I} / \mathrm{R}$ injury is different from hypoxic injury and it has been shown that hepatocytes with lower resting oxygen tensions may be more resistant to reperfusion injury. ${ }^{33}$ Oxidative stress was demonstrated to cause hepatocyte apoptosis mainly in PP and $\mathrm{MZ}$ areas. ${ }^{34-36}$ Our group too has previously presented evidence for ROS reaction with a lobular zonation, decreasing from PP to PC hepatocytes.17 This could explain the prevalence of

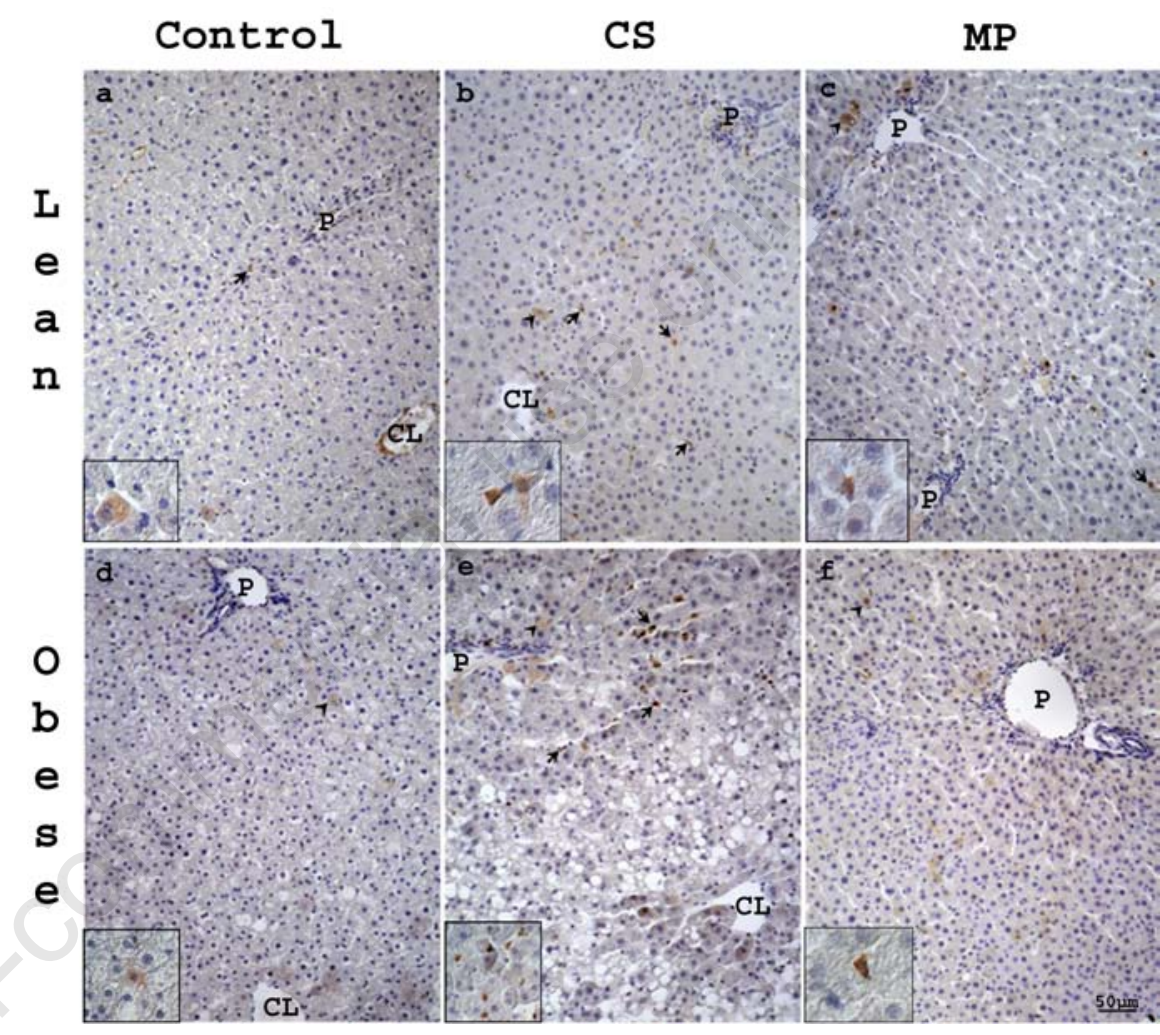

Figure 3. Representative light photomicrographs of caspase-3 stained sections from liver of lean (a-c) and obese (d-f) Zucker rats. In control lean (a) and obese (d) livers only few hepatocytes (arrow heads) and SLC (arrows) were caspase-3 positive. Both in lean and obese livers after CS (b, e) or MP20 (c, f), positive cells were located mainly in the MZ area. CL, centrolobular vein; $P$, portal vein. Scale bar: $50 \mu \mathrm{m}$.

a

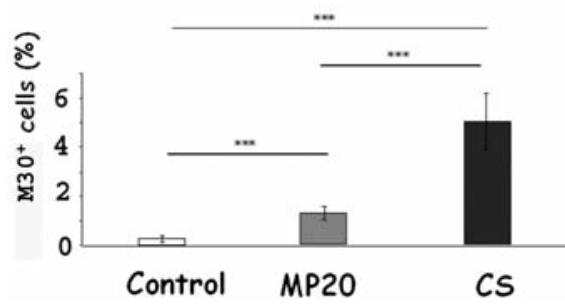

$\mathrm{b}$

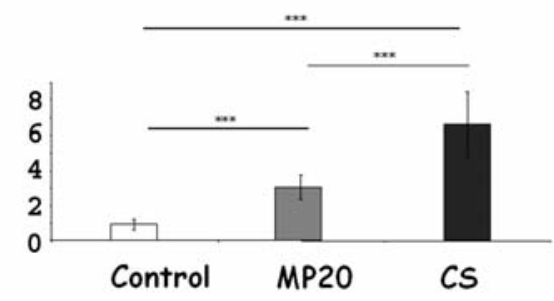

Figure 4. Apoptotic hepatocytes were quantified as the percentage of M30 positive cells/ total cells, in 10 random microscopic high-power fields (x40 objective). A statistically significant decrease of early apoptotic hepatocytes after MP20 respect to CS, both for obese (a) and lean (b) Zucker rat, was found (a, b). Values (\%) are reported as mean (5 rats for each group) \pm standard error; ${ }^{*} \mathrm{P}<0.05$. 
apoptotic hepatocytes in the PP area. A further explanation could be the different mitochondrial components and enzyme contents of PP and PC zones. ${ }^{37}$

Damage to SLC may be a major component of graft dysfunction after I/R injury, and since apoptosis is a major cause of SLC loss after I/R, limiting apoptosis may provide one therapeutic approach. ${ }^{38}$ Several studies established that in non-steatotic liver SLC are more injured than hepatocytes by cold preservation, also in terms of apoptotic cell death. ${ }^{39-43}$ The SLC remain viable upon oxygenated reperfusion of the graft but die rapidly thereafter in reimplanted grafts. ${ }^{44}$ Low temperature preservation causes injury to SLC, such as alteration of the extracellular matrix and cytoskeleton, ${ }^{40,45}$ detachment endothelial cells with loss of cytoplasmic processes lining the sinusoids ${ }^{46,47}$ and possibly Kupffer cell activation. ${ }^{48}$ SLC of FL are more prone to lose their viability after CS than those of normal liver. ${ }^{49}$ Damage of SLC can lead to impaired sinusoidal flow through adhesion and activation of circulating leukocytes, ${ }^{9}$ platelet activation,,$^{50}$ and ultimately a secondary injury to hepatocytes causing organ nonfunction or dysfunction after transplantation. ${ }^{51}$

In our study, apoptosis was observed mainly in SLC (sinusoidal endothelial cells, Kupffer cells, and stellate cells, as demonstrated by electron microscopy) and it was significantly higher in FL after CS respect to MP20. Probably, after CS apoptosis occurs during reperfusion, since it cannot occur in a milieu with low oxygen tension..$^{52}$ Indeed, although some components of SLC injury already occur during the preservation process,${ }^{53}$ SLC apoptosis is an active process that requires ATP as energy supply and the release of mediators such as TNF- $\alpha,{ }^{54,55}$ or the elevation of ATP levels; the latter are lowered in ischemic livers. ${ }^{56}$ The reduction of SLC apoptosis revealed by caspase- 3 expression and by the TUNEL assay, is in keeping with our previous biochemical data. Indeed, we have previously shown that MP20 greatly reduced TNF- $\alpha$ release as compared to CS, suggesting Kupffer cell protection when using subnormothermic temperature. ${ }^{17}$ The relevance of this protection is correlated to a reduction in the first source of ROS during reperfusion, thus limiting oxidant stress to hepatocytes. A further factor recognized as major mediator of apoptosis is oxidative stress. $^{57,58}$ We indeed reported a higher abundance of ROS-positive sinusoidal cells for CS than for MP20. ${ }^{17}$ Finally, we also previously reported that caspase- 3 activity, evaluated by $\mathrm{p}$ nitroaniline release, was lower with MP20 than with CS, thus confirming the reduction of apoptotic cell death. ${ }^{17}$

The reduction of apoptotic cells is important, since damaged SLC can exacerbate microcirculatory disturbances of $\mathrm{FL}^{59}$ and microcirculatory impairment has been implicated as an important mechanism in steatotic liver injury after transplantation., ${ }^{70}$ Reduced SLC apoptosis likely improves sinusoidal flow during reperfusion, decreases no-reflow phenomenon and leads to a reduction in secondary ischemic insults produced by flow disturbances. ${ }^{60}$ During reperfusion after MP20, we found a statistically significant decrease of portal pressure, respect to CS-preserved livers. The improvement of the flow in the sinusoids for FL preserved by MP20 can also be ascribed to the action of N-Acetylcysteine (NAC) included in the perfusion medium. NAC is not only a precursor of glutathione, therefore contributing to the protection against oxidative damage, ${ }^{61,62}$ but it also has vasorelaxant effects. ${ }^{63,64}$ Adding NAC to the liver before CS caused an amelioration of sinusoidal microcirculatory injury after cold I/R in steatotic rat liver. ${ }^{6}$

It is not possible to establish from the present data whether the damage to sinusoidal cells was caused by increased portal pressure or vice versa. It can be speculated that the IR

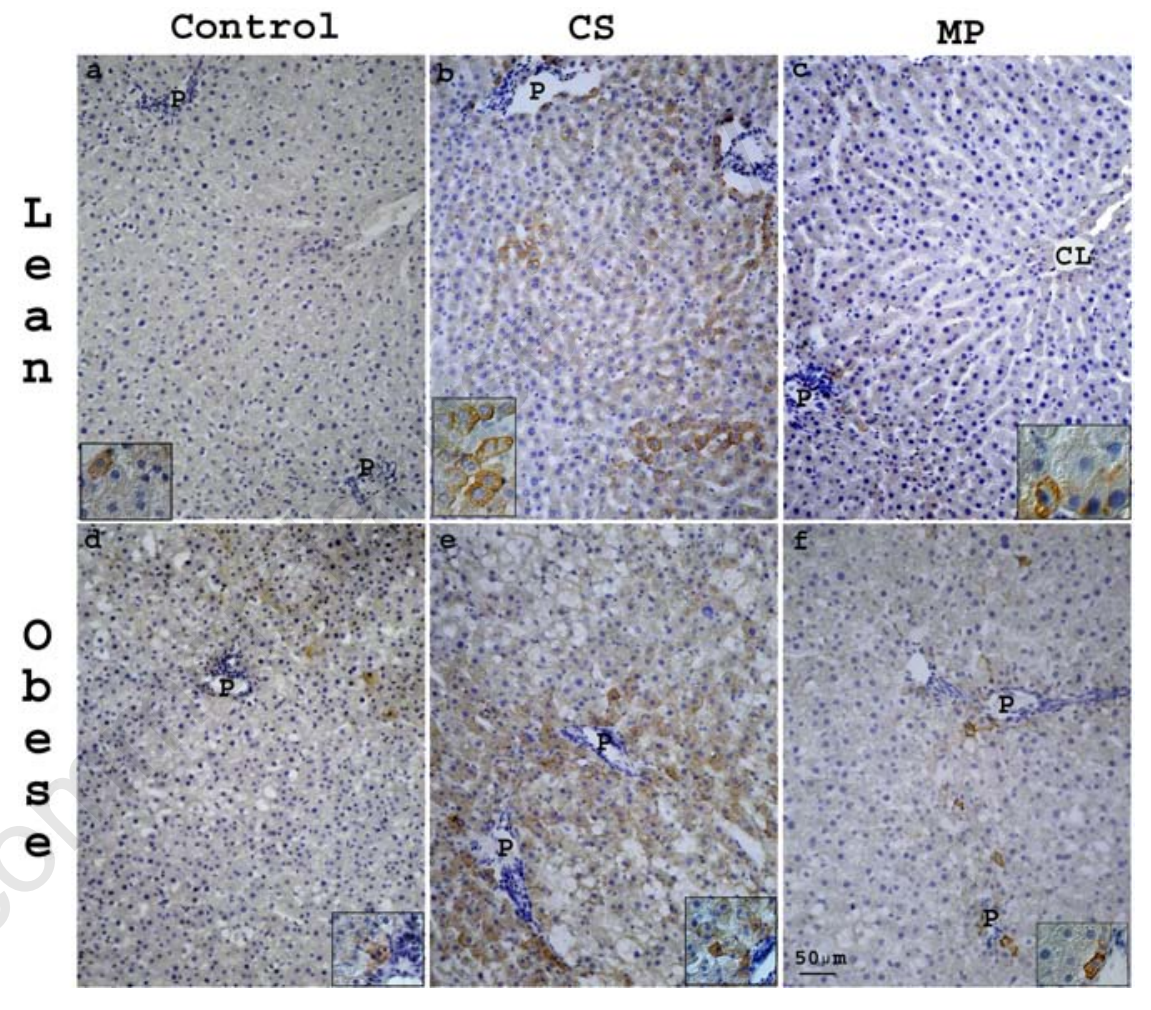

Figure 5. Representative light photomicrographs of M30 stained sections from liver of lean (a-c) and obese (d-f) Zucker rats. In lean (a) and obese (b) control livers minimal M30 staining was present. Both in lean and obese livers after CS (b,e) or MP20 (c,f), anti-M30 positive hepatocytes were mainly located in the PP and MZ regions and they showed a granular cytoplasmatic staining pattern. $C L$, centrolobular vein; $P$, portal vein. Scale bar: $50 \mu \mathrm{m}$.

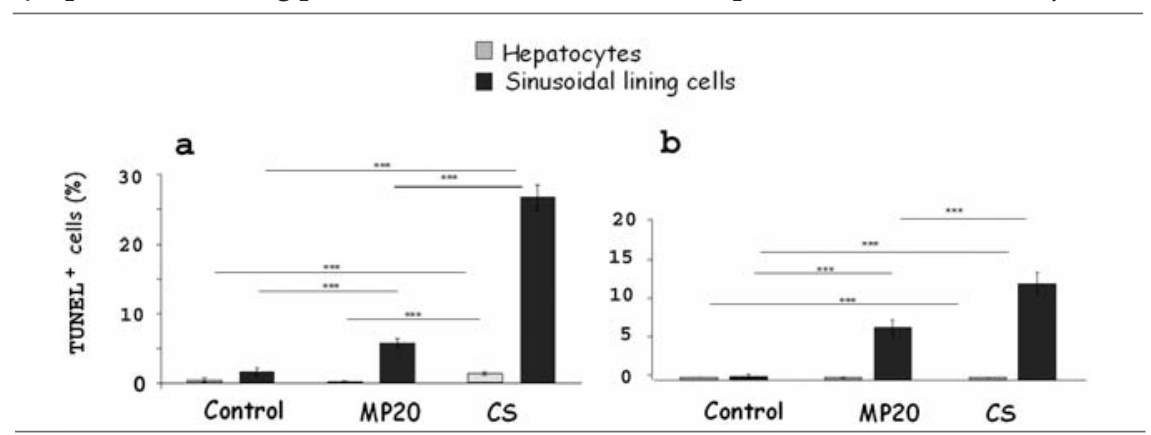

Figure 6. Hepatocytes and SLC death were quantified as the percentage of TUNEL positive cells/ total cells, in 15 random microscopic high-power fields (x40 objective). Statistically significant decrease of apoptotic hepatocytes and SLC after MP20 for obese Zucker rat was observed respect to CS (a). The same was observed in lean animals only for SLC (b). Values (\%) are reported as mean ( 5 rats for each group) \pm standard error; ${ }^{*} \mathrm{P}<0.05$. 
damage after $\mathrm{CS} / \mathrm{reperfusion}$ is the triggering cause for SLC apoptosis, and that the morphological changes of apoptotic cells hinder flow through the sinusoids thus contributing to increased portal pressure and initiating a vicious cycle of damage to the parenchyma.

Furthermore, limiting apoptosis is important, since apoptotic cells can be thrombogenic. Indeed, it has been demonstrated that apoptotic cells express phosphatidylserine on the cell surface membrane, essential for both thrombin generation and Tissue Factor (a procoagulant) activation. ${ }^{65}$ Finally, the decrease of apoptotic SLC is important, since the regeneration of these cells is more difficult than that of hepatocytes because it needs the mobilization of bone marrow precursors. ${ }^{66}$ Although the most relevant effect is the reduction of SLC

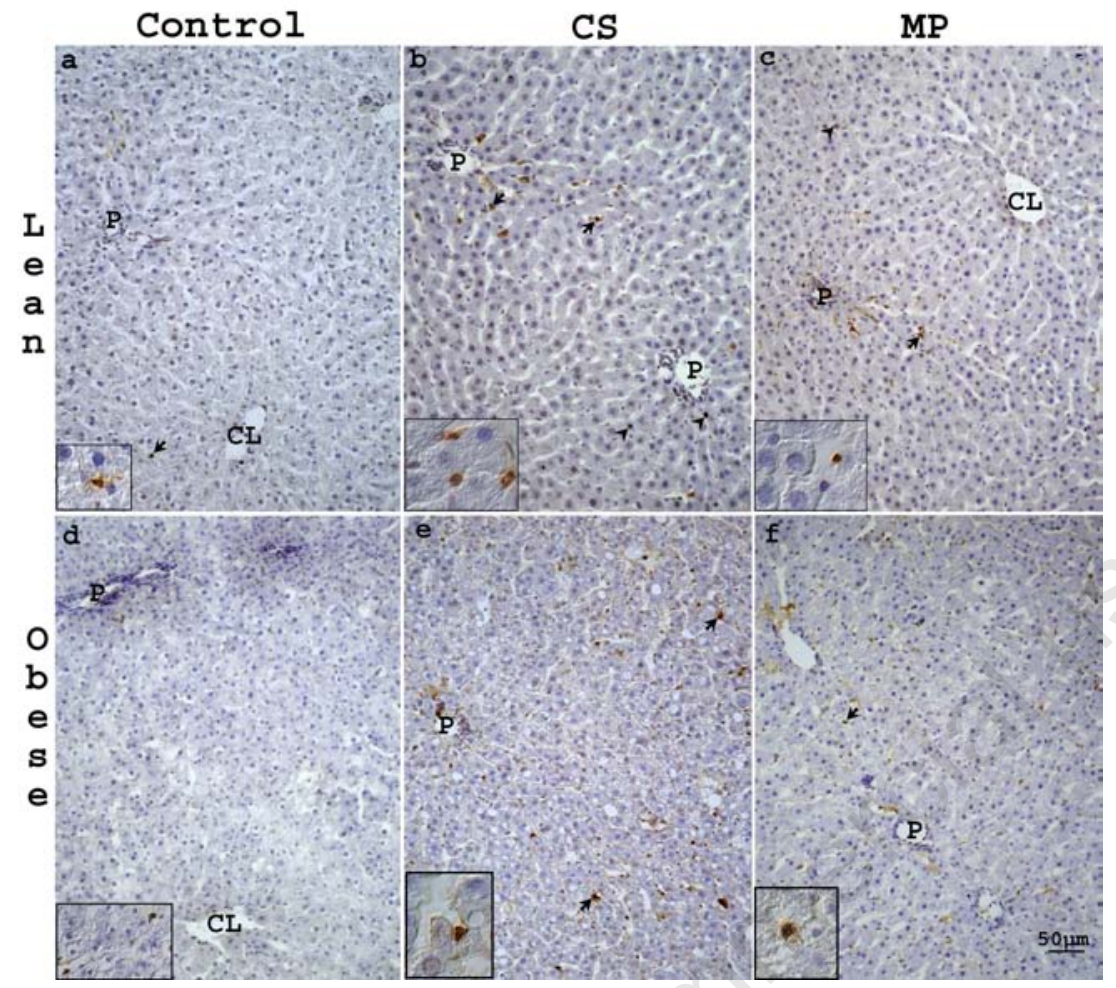

Figure 7. Representative light photomicrographs of TUNEL-stained sections from liver of lean (a-c) and obese (d-f) Zucker rats. In control lean (a) and obese (d) livers only few hepatocytes (arrow heads) and SLC (arrows) were TUNEL positive. Both in lean and obese livers after CS (b,e) or MP20 (c, f) TUNEL-stained cells were located mainly in PP and MZ area. $C L$, centrolobular vein; $P$, portal vein. Scale bar: $\mathbf{5 0} \mu \mathrm{m}$.
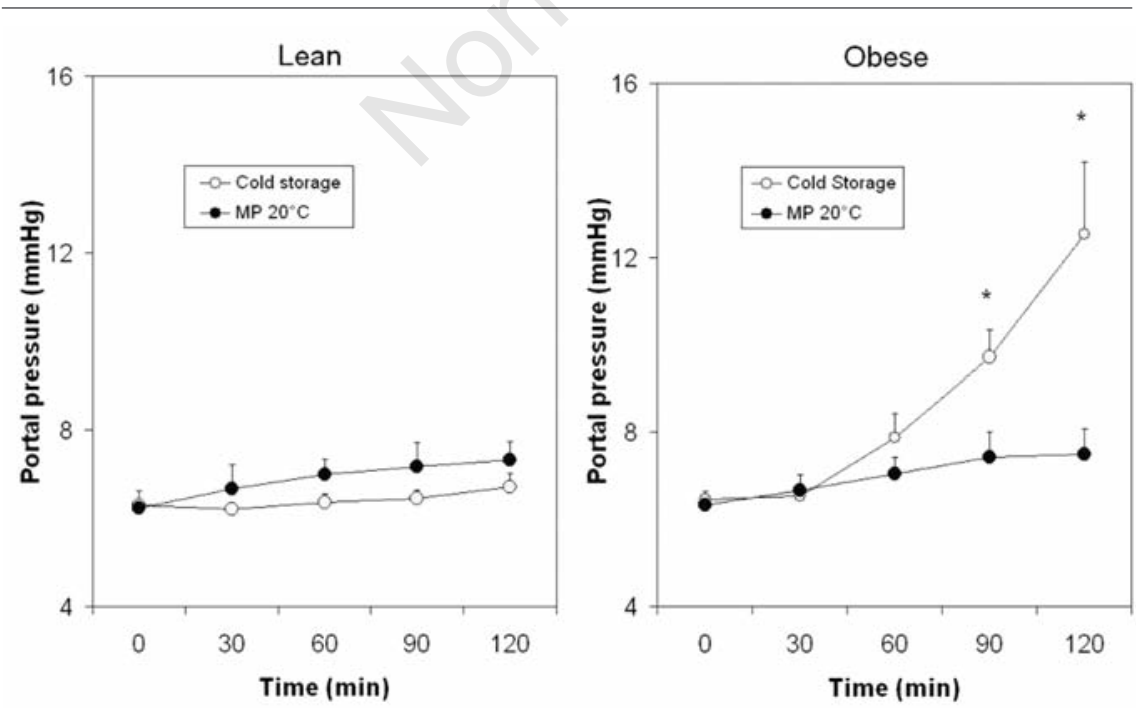

Figure 8. Portal pressure during reperfusion in lean and obese rats. Livers were preserved by $\mathrm{CS}$ or MP20 and submitted to normothermic reperfusion for $2 \mathrm{~h}$. Values $(\mathrm{mmHg})$ are reported as mean \pm standard error; ${ }^{*} \mathrm{P}<0.05$ vs MP $20^{\circ} \mathrm{C}$.

apoptosis after MP20 respect to $\mathrm{CS}$, also the decrease in hepatocyte death deserves mentioning since CS caused anyway early apoptotic features (expression of activated caspase 3 and M30) of parenchymal cells. Reducing both SLC and hepatocytes apoptosis is crucial in cases of mild or moderate steatosis. Results from recent clinical studies in humans and in animal models of steatosis suggest that the inhibition of apoptosis by ischemic preconditioning, ${ }^{15,67,68}$ or by pharmacological strategies protect against I/R injury. ${ }^{21}$

In conclusion, MP20 provides protection to FL, not only by significantly reducing hepatic enzymatic leakage, hepatic steatosis, and by increasing energy metabolism recovery during reperfusion, ${ }^{17}$ but also by reducing significantly SLC and hepatocyte apoptosis, thus potentially improving the quality of liver grafts without need of further protective strategies. These findings have important clinical implication since MP20 can render steatotic donor livers useable for transplantation.

\section{References}

1. Busuttil RW, Tanaka K. The utility of marginal donors in liver transplantation. Liver Transpl 2003;9:651-63.

2. Ploeg RJ, D'Alessandro AM, Knechtle SJ, Stegall MD, Pirsch JD, Hoffmann RM, et al. Risk factors for primary dysfunction after liver transplantation-a multivariate analysis. Transplantation 1993;55:807-13.

3. Marsman WA, Wiesner RH, Rodriguez L, Batts KP, Porayko MK, Hay JE, et al. Use of fatty donor liver is associated with diminished early patient and graft survival. Transplantation 1996;62:1246-51.

4. Nocito A, El-Badry AM, Clavien PA. When is steatosis too much for transplantation? J Hepatol 2006;45:494-9.

5. Koneru B, Reddy MC, dela Torre AN, Patel D, Ippolito T, Ferrante RJ. Studies of hepatic warm ischemia in the obese Zucker rat. Transplantation 1995;59:942-6.

6. Nakano H, Nagasaki H, Barama A, Boudjema K, Jaeck D, Kumada K, et al. The effects of $\mathrm{N}$-acetylcysteine and anti-intercellular adhesion molecule-1 monoclonal antibody against ischemia-reperfusion injury of the rat steatotic liver produced by a choline-methionine-deficient diet. Hepatology 1997;26:670-8.

7. Teramoto K, Bowers JL, Kruskai JB, Clouse ME. Hepatic microcirculatory changes after reperfusion in fatty and normal liver transplantation in the rat. Transplantation 1993;56:1076-82.

8. Minor T, Akbar S, Tolba R, Dombrowski F. Cold preservation of fatty liver grafts: pre- 
vention of functional and ultrastructural impairments by venous oxygen persufflation. J Hepatol 2000;32:105-11.

9. Hakamada K, Sasaki M, Takahashi K, Umehara Y, Konn M. Sinusoidal flow block after warm ischemia in rats with dietinduced fatty liver. J Surg Res 1997;70:1220.

10. Seifalian AM, Piasecki C, Agarwal A, Davidson BR. The effect of graded steatosis on flow in the hepatic parenchymal microcirculation. Transplantation 1999;68: 780-4.

11. Arnault I, Bao YM, Sebagh M, Anjo A, Dimicoli JL, Lemoine A, et al. Beneficial effect of pentoxifylline on microvesicular steatotic livers submitted to a prolonged cold ischemia. Transplantation 2003;76:7783.

12. Cortez-Pinto H, Lin HZ, Yang SQ, Da Costa S0, Diehl AM. Lipids upregulate uncoupling protein 2 expression in rat hepatocytes. Gastroenterology 1999;116:1184-93.

13. Caraceni P, Bianchi C, Domenicali M, Maria Pertosa A, Maiolini E, Parenti Castelli G, et al. Impairment of mitochondrial oxidative phosphorylation in rat fatty liver exposed to preservation-reperfusion injury. J Hepatol 2004;41:82-8.

14. Soltys K, Dikdan G, Koneru B. Oxidative stress in fatty livers of obese Zucker rats: rapid amelioration and improved tolerance to warm ischemia with tocopherol. Hepatology 2003;34:13-8.

15. Fernandez L, Carrasco-Chaumel E, Serafin A, Xaus C, Grande L, Rimola A, et al. Is ischemic preconditioning a useful strategy in steatotic liver transplantation? Am J Transplant 2004;4:888-99.

16. Bessems M, Doorschodt BM, Kolkert JL, Vetelainen RL, van Vliet AK, Vreeling $\mathrm{H}$, et al. Preservation of steatotic livers: a comparison between cold storage and machine perfusion preservation. Liver Transpl 2007;13:497-504.

17. Vairetti M, Ferrigno A, Carlucci F, Tabucchi A, Rizzo V, Boncompagni E, et al. Subnormothermic machine perfusion protects steatotic livers against preservation injury: a potential for donor pool increase? Liver Transpl 2009;15:20-9.

18. Ferrigno A, Carlucci F, Tabucchi A, Tommassini V, Rizzo V, Richelmi P, et al. Different susceptibility of liver grafts from lean and obese Zucker rats to preservation injury. Cryobiology 2009;59:327-34.

19. Selzner M, Rudiger HA, Sindram D, Madden J, Clavien PA. Mechanisms of ischemic injury are different in the steatotic and normal rat liver. Hepatology 2000;32:1280-8.

20. Choi S, Noh J, Hirose R, Ferell L, Bedolli M, Roberts JP, et al. Mild hypothermia pro- vides significant protection against ischemia/reperfusion injury in livers of obese and lean rats. Ann Surg 2005;241:470-6.

21 Laurens M, Scozzari G, Patrono D, St-Paul MC, Gugenheim J, Huet PM, et al. Warm ischemia-reperfusion injury is decreased by tacrolimus in steatotic rat liver. Liver Transpl 2006;12:217-25.

22. Baskin-Bey ES, Canbay A, Bronk SF, Werneburg N, Guicciardi ME, Nyberg SL, et al. Cathepsin B inactivation attenuates hepatocyte apoptosis and liver damage in steatotic livers after cold ischemia-warm reperfusion injury. Am J Physiol Gastro intest Liver Physiol 2005;288:396-402.

23. Sun Z, Klein AS, Radaeva S, Hong F, ElAssal 0, Pan HN, et al. In vitro interleukin-6 treatment prevents mortality associated with fatty liver transplants in rats. Gastroenterology 2003;125:202-15.

24. Collins JA, Schandi CA, Young KK, Vesely J, Willingham MC. Major DNA fragmentation is a late event in apoptosis. J Histochem Cytochem 1997;45:923-34.

25. Schulze-Osthoff K, Walczak H, Dröge W, Krammer PH. Cell nucleus and DNA fragmentation are not required for apoptosis. J Cell Biol 1994;127:15-20.

26. Gujral JS, Bucci TJ, Farhood A, Jaeschke $\mathrm{H}$. Mechanism of cell death during warm hepatic ischemia-reperfusion in rats: apoptosis or necrosis? Hepatology 2001; 33:397-405.

27. Grasl-Kraupp B, Ruttkay-Nedecky B, Koudelka H Bukowska K, Bursch W, Schulte-Hermann R. In situ detection of fragmented DNA (TUNEL assay) fails to discriminate among apoptosis, necrosis, and autolytic cell death: a cautionary note. Hepatology 1995;21:1465-8.

28. Caulin C, Salvesen GS, Oshima RG. Caspase cleavage of keratin 18 and reorganization of intermediate filaments during epithelial cell apoptosis. J Cell Biol 1997;138:1379-94.

29. Leers MP, Kölgen W, Björklund V, Bergman T, Tribbick G, Persson B, et al. Immunocytochemical detection and mapping of a cytokeratin 18 neo-epitope exposed during early apoptosis. J Pathol 1999;187: 567-72.

30. Omary MB, Ku NO, Toivola DM. Keratins: Guardians of the liver. Hepatology 2002;35:251-7.

31. Zatloukal K, Stumptner C, Fuchsbichler A, Fickert $\mathrm{P}$, Lackner $\mathrm{C}$, Trauner M, et al. The keratin cytoskeleton in liver diseases. J Pathol 2004;204:367-76.

32. Koteish A, Mae Diehl A. Animal models of steatohepatitis. Best Pract Res Clin Gastroenterol 2002;16:679-90.

33. Topaloglu S, Abbasoglu 0, Ayhan A, Sokmensuer C, Kilinc K. Antiapoptotic and protective effects of roscovitine on ischemia-reperfusion injury of the rat liver. Liver Int 2003;23:300-7.

34. Kato Y, Tanaka J, Koyama K. Intralobular heterogeneity of oxidative stress and cell death in ischemia-reperfused rat liver. $\mathrm{J}$ Surg Res 2001;95:99-106.

35. Sasaki H, Matsuno T, Nakagawa K, Tanaka $\mathrm{N}$. Induction of apoptosis during early phase of reperfusionafter rat liver ischemia. Acta Med Okayama 1997;51:30512 .

36. Suematsu M, Suzuki H, Ishii H, Kato S, Yanagisawa T, Asako H, et al. Early midzonal oxidative stress preceding cell death in hypoperfused rat liver. Gastroenterology 1992;103:994-1001.

37. Jungermann K, Katz N. Functional hepatocellular heterogeneity. Hepatology 1982;2: 385-95.

38. Georgiev P, Clavien PA, Gores GJ. Liver graft protection by antiapoptotic drugs: a step further. Liver Transpl 2007;13:318-20.

39. McKeown CMB, Edwards V, Phillips MJ, Harvey PRC, Petrunka CN, Strasberg SM. Sinusoidal lining cell damage: the critical injury in cold preservation of liver allografts in the rat. Transplantation 1988; 46:178-91.

40. Holloway CMB, Harvey PRC, Strasberg SM. Viability of sinusoidal lining cells in coldpreserved rat liver allografts. Transplantation 1990;49:225-9.

41. Lemasters JJ. Hypoxic, ischemic and reperfusion injury to liver. In: IM Arias, JL Boyer, FV Chisari, N Fausto, D Schachter, DA Shafritz (eds.) The Liver: Biology and Pathobiology, pp 258-279. Philadelphia: Lippincott Williams \& Wilkins, 2001.

42. Kukan M, Haddad PS. Role of hepatocytes and bile duct cells in preservation-reperfusion injury of liver grafts. Liver Transpl 2001;7:381-400.

43. Miyagawa Y, Imamura $\mathrm{H}$, Soeda $\mathrm{J}$, Matsunaga K, Mochida S, Fujiwara K, et al. Fate of hepatocyte and sinusoidal lining cell function and kinetics after extended cold preservation and transplantation of the rat liver. Liver Transpl 2002;8:370-81.

44. Clavien PA, Harvey PR, Strasberg SM. Preservation and reperfusion injuries in liver allografts. An overview and synthesis of current studies. Transplantation 1992; 53:957-78.

45. Caldwell-Kenkel JC, Thurman RG, Lemasters JJ. Selective loss of nonparenchymal cell viability after cold ischemic storage of rat livers. Transplantation 1988;45:834-7.

46. Momii S, Koga A. Time-related morphological changes in cold-stored rat livers. A comparison of Euro-Collins solution with UW solution. Transplantation 1990;50:745- 
50.

47. Fratté S, Gendrault JL, Steffan AM, Kirn A. Comparative ultrastructural study of rat livers preserved in Euro-Collins or UW Solution. Hepatology 1991;13:1173-80.

48. Thurman RG, Cowper KC, Marzi I , Currin $\mathrm{R}$, Lemasters JJ. Functional activation of Kupffer cells by cold ischemic storage of rat liver in Euro-Collins solution. Hepatology 1988;8:1824-7.

49. Fukumori T, Ohkohchi N, Tsukamoto S, Satomi S. Why is fatty liver unsuitable for transplantation? Deterioration of mitochondrial ATP synthesis and sinusoidal structure during cold preservation of a liver with steatosis. Transplant Proc 1997;29:412-5.

50. Panés J, Granger N. Leukocyte-endothelial cell interactions: Molecular mechanisms and implications in gastrointestinal disease. Gastroenterology 1998;114:1066-90.

51. Lemasters JJ, Thurman RG. Reperfusion injury after liver preservation for transplantation. Annu Rev Pharmacol Toxicol 1997;37:327-38.

52. Stefanelli C, Stanic I, Bonavita F, Muscari C, Pignatti C, Rossoni C, et al. Oxygen tension influences DNA fragmentation and cell death in glucocorticoid-treated thymocytes. Biochem Bioph Res Commun 1995;212:300-5.

53. Clavien PA. Sinusoidal endothelial cell injury during hepatic preservation and reperfusion. Hepatology 1998;28:281-5.

54. Nicotera P, Leist M, Ferrando-May E. Intracellular ATP, a switch in the decision between apoptosis and necrosis. Toxicol Lett 1998;102-103:139-42.

55. Colletti LM, Kunkel SL, Walz A, Burdick MD, Kunkel RG, Wilke CA, et al. The role of cytokine networks in the local liver injury following hepatic ischemia/reperfusion in the rat. Hepatology 1996;23:506-14.

56. Elimadi A, Settaf A, Morin D, Sapena R, Lamchouri F, Cherrah Y, et al. Trimetazidine counteracts the hepatic injury associated with ischemia-reperfusion by preserving mitochondrial function. J Pharmacol Exp Ther 1998;286:23-8.

57. Jones BE, Lo CR, Liu H, Pradhan Z, Garcia L, Srinivasan A, et al. Role of caspase and NF-kappa B signaling in hydrogen peroxide and superoxide induced hepatocyte apoptosis. Am J Physiol Gastrointest Liver Physiol 2000;278:G693-9.

58. Guicciardi ME, Gores GJ. Apoptosis: a mechanism of acute and chronic liver injury. Gut 2005;54:1024-33.

59. Fukumori T, Ohkohchi N, Tsukamoto S, Satomi S. Why is a liver with steatosis susceptible to cold ischemic injury? Transplant Proc 1999;31:548-9.

60. Hoglen NC, Anselmo DM, Katori M, Kaldas M, Shen XD, Valentino KL, et al. A caspase inhibitor, IDN-6556, ameliorates early hepatic injury in an ex vivo rat model of warm and cold ischemia. Liver Transpl 2007;13:361-6.

61. Han J, Paik YH, Yu JH, Kim H. Antioxidant nutrients inhibit LPS-induced IL-8 expression in human hepatic stellate cells. Faseb J 2007;21:855.8.
62. Keles MS, Demirci N, Yildirim A, Atamanalp SS, Altinkaynak K. Protective effects of $\mathrm{N}$-acetylcysteine and Ginkgo biloba extract on ischaemia-reperfusioninduced hepatic DNA damage in rats. Clin Exp Med 2008;8:193-8.

63. Harrison PM, Wendon JA, Gimson AES, Alexander GJM, Williams R. Improvement by acetylcysteine of hemodynamics and oxygen transportin fulminant hepatic failure. N Engl J Med 1991;324:1852-7.

64. Koeppel TA, Thies JC, Lehmann T, Gebhard MM, Herfarth C, Otto G, et al. Improvement of hepatic microhemodynamics by $\mathrm{N}$-acetylcysteine after warm ischemia. Eur Surg Res 1996;28:270-7.

65. Wang J, Weiss I, Svoboda K, Kwaan HC. Thrombogenic role of cells undergoing apoptosis. Br J Haematol 2001;115:382-91.

66. Zhu J, Wang S, Bie P, Li X, Zhang Y, Xiong $\mathrm{Y}$, et al. Apoptosis and regeneration of sinusoidal endothelial cells after extended cold preservation and transplantation of rat liver. Transplantation 2007;84:1483-91.

67. Clavien PA, Yadav S, Sindram D, Bentley RC. Protective effects of ischemic preconditioning for liver resection performed under inflow occlusion in humans. Ann Surg 2000;232:155-62.

68. Selzner N, Selzner M, Jochum W, Clavien PA. Ischemic preconditioning protects the steatotic mouse liver against reperfusion injury: an ATP dependent mechanism. J Hepatol 2003;39:55-61. 